\title{
Implementasi Manajemen Bank Sampah IT pada Komunitas Bank Sampah berbasis Masyarakat, Pemuda, dan Sekolah di Kabupaten Pasuruan
}

\author{
Amang Fathurrohman ${ }^{1}$, M. Dayat ${ }^{1}$, Zainul Ahwan ${ }^{1}$, M. Daimul Abror ${ }^{1}$, Lukman Hakim $^{1}$, \\ Syukur Sugeng Apriwiyanto ${ }^{2}$, Imam Syafi' ${ }^{3}$, Fafit Rahmat Aji ${ }^{4}$, Mulyono Wobisono ${ }^{4}$ \\ ${ }^{1}$ Universitas Yudharta Pasuruan, ${ }^{2}$ Yayasan Investasi Sosial Indonesia, ${ }^{3}$ Universitas Sunan Giri \\ Surabaya, ${ }^{4}$ PT. Tirta Investama Pabrik Pandaan \\ amangfr@yudharta.ac.id,dayat@yudharta.ac.id, zezen@yudharta.ac.id, daim@yudharta.ac.id, \\ lukman@yudharta.ac.id, apri_reog@yahoo.co.id, ahsyafii1@gmail.com, fafit.aji@,danone.com, \\ mulyono.wibisono@danone.com
}

\begin{abstract}
Abstrak. Waste is still a problem in Indonesia. Because of waste, especially organic waste, contributes greatly to climate change due to greenhouse gases. In the management of waste that is generally open damping, particularly in Pasuruan, until now is still a problem that has not been unsolved. Therefore, the author will be presented in the study of implementation of integrated waste management based on IT and obstacles faced during the mentoring process. This mentoring activity was carried out at four Waste Banks based on community, schools, and youth in Pasuruan Regency with Community-Based Research (CBR) approach. The results showed that the various activities of W aste Bank application management mentoring based on IT gained widespread acceptance and appreciation from the Manager of Waste Bank in Pasuruan Regency. However, in the process of transition from Waste Bank management from manual-based until there was a change by utilizing IT required a process, time as well as the willingness of $W$ aste Bank. Manager, so that these applications could be fully utilized. In addition, the different types of community and management differences developed in Waste Bank also affected in the utilization of this $W$ aste Bank Application to be applied continuously in their community.
\end{abstract}

Keywords: Waste Bank Application, Integrated Waste Management

\section{Pendahuluan}

Pemanasan global akibat kenaikan Gas Rumah Kaca, yang disebabkan peningkatan Karbon Dioksida $\left(\mathrm{CO}^{2}\right)$ dan Gas Metana $\left(\mathrm{CH}^{4}\right)$, berimplikasi kepada perubahan iklim yang cukup ekstrim. Hal ini bisa dilihat dari perubahan fluktuasi curah hujan yang tinggi dan kenaikan muka laut ${ }^{1}$.

Selain itu, perubahan iklim juga berimplikasi di berbagai sektor. Di bidang Pertanian, kajian dari Suryo Wiyono mengungkapkan bahwa perubahan iklim juga berdampak pada ledakan hama

1 Armi Susandi et al., "Dampak Perubahan Iklim Terhadap Ketinggian Muka Laut Di Wilayah Banjarmasin," Jurnal Ekonomi Lingkungan 12, no. 2 (2008): 5-8, http://blog.umy.ac.id/ghea/files/2011/12/Dampak-PerubahanIklim-Terhadap-Ketinggian-Muka-Laut-Banjarmasin.pdf.

Volume 2, Number 2, November 2018 | 154 Implementasi Manajemen Bank Sampah IT pada Komunitas Bank Sampah berbasis Masyarakat, Pemuda, dan Sekolah di Kabupaten Pasuruan 


\section{ENGAGEMENT}

Jurnal Pengabdian Kepada Masyarakat

ISSN : 2579-8375 (Print)

ISSN : 2579-8391 (Online)

dan penyakit tanaman ${ }^{2}$. Di bidang kajian kelautan, dampak perubahan iklim bisa dibaca dalam kajian Armi Susandi, dkk yang memproyeksikan Kota Banjarmasin pada tahun 2.100 akan mengalami kenaikan air laut sebesar 0.934 yang akan berdampak terhadap menggenangnya air laur di wilayah Banjarmasin dan mengakibatkan rusaknya berbagai sarana dan prasarana di wilayah tersebut ${ }^{3}$. Di Bidang ekonomi, sebagaimana dilansir dalam Agenda Rencana Aksi Nasional dalam Menghadapi Perubahan Iklim yang digagas oleh Kementerian Negara Lingkungan Hidup tahun 2007. Dalam latar belakangnya mengungkapkan bahwa akibat bencana iklim diperkirakan tahun 2.050, apabila pemanasan global terus terjadi dan tidak ada upaya-upaya adaptasi yang terencana dilakukan dari sekarang, maka diperkirakan kerugian ekonomi akibat bencana iklim akan meningkat mencapai 300 Milyar Dolar per-Tahun dan jumlah kematian bisa mencapai 100 Ribu Orang per-Tahun ${ }^{4}$.

Oleh karena itu, berbagai upaya berbagai pihak untuk meminimalisir peningkatan Gas Rumah Kaca terus digalakkan, khususnya mereduksi berbagai aktifitas yang berpotensi memberikan sumbangsih Karbon Dioksida $\left(\mathrm{CO}^{2}\right)$ dan Gas Metana $\left(\mathrm{CH}^{4}\right)$, salah satunya timbulan sampah yang tidak terkelola dengan baik. Hal ini diperkuat dengan laporan IPCC pada tahun 2006 sebagaimana dikutip oleh Wahyu Purwanta yang menyatakan bahwa sektor limbah (waste sector), khusus dari TPA-TPA sampah, telah memberikan kontribusi GRK ke atmosfer antara $3-4 \%$ dari emisi GRK global. Dari Laporan IPCC tersebut dan dari hasil kajian Wahyu Purwanta semakin memperkuat bahwa bahwa potensi gas metan dari sektor sampah di Indonesia sangat besar yakni sekitar 109,96 Gg per tahun dimana terdapat l.k 400 TPA yang hampir semuanya beroperasi secara open dumping. Sebagian besar gas ini dihasilkan dari proses degradasi sampah taman, kayu dan sampah sisa makanan. Selain itu tingginya potensi gas metan ini uga disebabkan kondisi TPA Indonesia yang umumnya ‘basah’ akibat iklim dan juga komposisi sampah organiknya yang hampir $60 \%-70 \% 5$.

Apabila dikontekkan dengan kondisi tata kelola sampah di Kabupaten Pasuruan, dapat dinyatakan bahwa Kabupaten Pasuruan juga memberikan sumbangsih GRK yang signifikan, karena Kabupaten Pasuruan dalam tata kelola sampah masih jauh dari sempurna, bahkan bisa

2 Suryo Wiyono, "Perubahan Iklim Dan Ledakan Hama Dan Penyakit Tanaman," Perubahan Iklim Dan Ledakan Hama Dan Penyakit Tanaman (Jakarta: KEHATI, 2007), http://repository.ipb.ac.id/handle/123456789/30756.

3 Susandi et al., "Dampak Perubahan Iklim Terhadap Ketinggian Muka Laut Di Wilayah Banjarmasin."

${ }^{4}$ Kementerian Negara Lingkungan Hidup, Rencana Aksi Nasional Dalam Menghadapi Perubahan Iklim (Indonesia, 2007).

5 Wahyu Purwanta, "Penghitungan Emisi Gas Rumah Kaca (GRK) Dari Sektor Sampah Perkotaan Di Indonesia," Jurnal Teknik Lingkungan 10, no. 1 (2009): 1-8.

Volume 2, Number 2, November 2018 | 155 Implementasi Manajemen Bank Sampah IT pada Komunitas Bank Sampah berbasis Masyarakat, Pemuda, dan Sekolah di Kabupaten Pasuruan 


\section{ENGAGEMENT}

Gurnal Pengabdian Kepada Masyarakat

ISSN : 2579-8375 (Print)

ISSN : 2579-8391 (Online)

dinyatakan pada situasi "darurat sampah". 6 Selain itu, secara umum Bank Sampah di kabupaten Pasuruan masih belum maksimal dalam manajemen tata kelolanya, sehingga kontribusi Bank Sampah untuk mengurai sampah di Kabupaten Pasuruan belum maksimal. Oleh karena itu, maka kajian ini akan menguraikan hasil pendampingan 4 Komunitas Bank Sampah di Kabupaten Pasuruan dengan basis masyarakat, pemuda, dan sekolah terkait dengan implementasi tata kelola Bank Sampah berbasis IT.

\section{Metode Dampingan}

Pendekatan yang dikembangkan dalam kajian ini adalah Community Based Research, ${ }^{7,8}$ dengan melakukan proses pendampingan 4 komunitas Bank Sampah dengan basis yang berbeda, yakni berbasis masyarakat (Bank Sampah TPI Beji), pemuda (Bank Sampah OPEK Gempol), dan sekolah (Bank Sampah TK. Al-Hidayah dan PAUD Wanjati Pandaan). Adapun waktu pendampingan dilaksanakan bulan Agustus 2017-September 2018.

\section{Penyajian Pendampingan Masyarakat}

\section{Profil Singkat Komunitas Dampingan}

Sebagaimana dalam paparan di atas, maka dalam kajian ini akan dipaparkan secara singkat 4 komunitas Bank Sampah dampingan untuk mengimplementasikan manajemen Bank Sampah berbasis IT, diantaranya Bank Sampah TPI Beji, Bank Sampah OPEK Gempol, Bank Sampah TK Al-Hidayah dan PAUD Wanjati Pandaan.

Pertama, Bank Sampah TPI Beji Pasuruan. Bank Sampah ini merupakan salah satu Bank Sampah berbasis masyarakat yang diprakarsai oleh Komunitas Ibu-ibu PKK Perumahan Taman Permata Indah (TPI) Beji Pasuruan. Para-ibu-ibu yang tergabung dalam kepengurusan Bank Sampah ini sejak awal tahun 2010 dengan rincian 10 pengurus dan 80 nasabah ini, telah menghasilkan tata kelola Bank Sampah dengan baik, namun masih dicatat melalui buku Tabungan Bank Sampah yang dicatat secara manual.

Transaksi Bank Sampah yang dilakukan oleh Bank Sampah TPI rutin dilakukan seminggu

\footnotetext{
${ }^{6}$ Rossi, "Jumlah Bank Sampah Jauh Dari Ideal," Kabarbromoterkini.Com, last modified 2015, accessed May 4, 2017, http://www.kabarbromoterkini.com/2015/04/24/jumlah-bank-sampah-jauh-dari-ideal/3/.

7 Tim Penyusun CBR UIN Sunan Ampel Surabaya, Community Based Research: Sebuah Pengantar (Surabaya: SILE/LLD, 2015).

${ }^{8}$ Lihat metode CBR dalam artikel Amang Fathurrohman, "Rintisan Pendidikan Anak Usia Dini Suku Tengger Di Wilayah Terpencil Dusun Surorowo Desa Kayukebek Kecamatan Tutur Kabupaten Pasuruan,” in 1st Annual Conference for Muslim Scholars Kopertais Wilayah IV Surabaya (Surabaya: Kopertais Wilayah IV Surabaya, 2017), 408-416, http://proceedings.kopertais4.or.id/index.php/ancoms/article/view/42.
}

Volume 2, Number 2, November 2018| 156 Implementasi Manajemen Bank Sampah IT pada Komunitas Bank Sampah berbasis Masyarakat, Pemuda, dan Sekolah di Kabupaten Pasuruan 


\section{ENGAGEMENT}

Gurnal Pengabdian Kepada Masyarakat

ISSN : 2579-8375 (Print)

ISSN : 2579-8391 (Online)

sekali bersamaan dengan agenda pertemuan ibu-ibu PKK di Perumahan tersebut. Para anggota PKK sekaligus nasabah Bank Sampah TPI membawa beragam sampah ekonomis untuk dikumpulkan dan dijual pada pengurus Bank Sampah, sehingga sampah rumah tangga yang menumpuk memiliki nilai tambah ekonomis bagi kebutuhan rumah tangga mereka. ${ }^{9}$

Kedua, Bank Sampah OPEK Gempol. Bank Sampah yang digerakkan oleh Para Pemudapemudi karang Taruna ini memiliki dedikasi dan tekad untuk mengembangkan lingkungan bebas sampah khususnya di lingkungan Dusun Kemuning Desa Sumbersuko Kecamatan Gempol Kabupaten Pasuruan. Bank Sampah yang sudah berdiri sejak tahun 2013 dengan dikelola 12 pengurus BANK SAMPAH dan 117 nasabah ini memiliki 3 fokus pengelolaan sampah, yakni: (1) Pengelolaan sampah an organik dengan mengolahnya menjadi produk handycraft; (2) Mengolah sampah organik menjadi pupuk kompos; dan (3) Melestarikan penghijauan di desa Sumbersuko. ${ }^{10}$

Ketiga, Bank Sampah TK Al-Hidayah dan PAUD Wanjati Pandaan. Kedua sekolah yang berlokasi di Desa Karangjati Kecamatan Pandaan Kabupaten Pasuruan tersebut memiliki kesamaan untuk mengembangkan pendidikan lingkungan di sekolah mereka dengan pendekatan SCALLING (Sekolah Cerdas, Peduli dan Berbudaya Lingkungan). ${ }^{11}$ Kedua sekolah tersebut juga telah mengembangkan program Shodaqoh Sampah ${ }^{12}$ sebagai bagian dari implementasi Bank Sampah di sekolah mereka yang dilakukan setiap hari Sabtu untuk TK Al-Hidayah dan setiap hari Kamis untuk PAUD Wanjati.

\section{Research Planning, Information Gathering and Analysis: Tata Kelola Bank Sampah di Kabupaten Pasuruan}

Tata kelola sampah di Kabupaten Pasuruan sudah pada level darurat sampah. Hal ini didasarkan data bahwa Kabupaten Pasuruan masih memiliki 1 (satu) TPA yang beroperasi di

${ }_{9}$ Amang Fathurrohman et al., Inisiasi Tata Kelola Manajemen Bank Sampab Berbasis IT Pada Komunitas Bank Sampah Berbasis Sekolah, Pemuda, Dan Masyarakat Di Kabupaten Pasuruan (Kabupaten Pasuruan, 2018).

${ }^{10}$ Ibid.

${ }^{11}$ Fafit Rahmat Aji et al., "Pengembangan PAUD Pro-Lingkungan Hidup Melalui Scalling Dalam Program Integrated Community Development (ICD) PT. TIV.," At-Tajdid: Jurnal Ilmu Tarbiyah 5, no. 1 (2016): 129-150, accessed April 29, 2017, http:/ / ejournal.stitmuh-pacitan.ac.id/index.php/attajdid/article/view/78.

12 Amang Fathurrohman et al., "Shodaqoh Sampah Usia Dini: Implementasi Program Shodaqoh Sampah Pada Pendidikan Usia Dini Wanjati Junior Pandaan Pasuruan,” PROCEEDINGS: Annual Conference for Muslim Scholars 1, no. Series 2 (2018): 711-720.

Volume 2, Number 2, November 2018| 157 Implementasi Manajemen Bank Sampah IT pada Komunitas Bank Sampah berbasis Masyarakat, Pemuda, dan Sekolah di Kabupaten Pasuruan 


\section{ENGAGEMENT}

Jurnal Pengabdian Kepada Masyarakat

ISSN : 2579-8375 (Print)

ISSN : 2579-8391 (Online)

Kenep Beji Pasuruan dengan kondisi overload kapasitas daya tampung sampahnya. ${ }^{13,14}$ Selain itu, dalam tata kelola sampah di Kabupaten Pasuruan masih menggunakan metode 3P (Pengumpulan, Pengangkutan dan Pembuangan), yakni sampah dikumpulkan dari sumbernya dan diangkut ke tempat penampungan sementara (TPS) lantas diangkut lagi ke tempat pembuangan akhir (TPA) ${ }^{15}$. Tentu metode tersebut masih memunculkan persoalan terkait bau busuk, berkembang-biaknya ribuan lalat, sarang nyamuk, tikus, dan sampah tercecer ke jalanan dan got sehingga terkesan kumuh dan dapat mengakibatkan banjir. ${ }^{16}$

Selain keterbatasan tenaga dan sarana dalam tata kelola sampah, partisipasi masyarakat untuk mengurai sampah juga masih rendah. Hal ini bisa dilihat dari Upaya Pemerintah Kabupaten Pasuruan untuk mengembangkan program Satu Desa Satu Bank Sampah (SDSB) ${ }^{17}$ sejak tahun 2015, ${ }^{18}$ namun sampai dengan November 2017, jumlah Bank Sampah di Kabupaten Pasuruan masih 33 komunitas. ${ }^{19}$ Jumlah yang sangat jauh dari ideal apabila dibandingkan dengan jumlah Desa di Kabupaten Pasuruan yang mencapai 24 Kelurahan dan 341 Desa. ${ }^{20}$

Selain itu, serta kondisi riil Bank Sampah sampai saat ini masih belum berjalan dengan maksimal, khususnya dalam tata kelola manajemen Bank Sampah yang semuanya masih menggunakan catatan manual dalam proses transaksinya, sehingga tidak sedikit Bank Sampah tidak berjalan dengan baik karena transparansi dan manajemen tata kelola Bank Sampah yang beum maksimal. Oleh karena itu, salah satu solusi untuk meningkatkan partisipasi masyarakat serta kemudahan manajemen tata kelola sampah maka Tim Pendamping dari multistakeholders mendorong agar pengelola Bank Sampah memiliki kapasitas dan kemampuan manajerial tata kelola

13 “Tuntaskan TPA Kenep, Bebaskan 2250 M2 Lahan,” Pasuruankab.Go.Id, accessed January 23, 2016, pasuruankab.go.id/berita-2077-tuntaskan-tpa-kenep-bebaskan-2250-m2-lahan.html.

14 Muhammad Fahmi, “2018, Wajah TPA Kenep Bakal Berubah Jadi Begini,” Radar Bromo, last modified 2017, accessed September 29, 2018, https://radarbromo.jawapos.com/read/2017/11/02/23918/2018-wajah-tpakenep-bakal-berubah-jadi-begini.

${ }^{15}$ Fathurrohman et al., "Shodaqoh Sampah Usia Dini: Implementasi Program Shodaqoh Sampah Pada Pendidikan Usia Dini Wanjati Junior Pandaan Pasuruan."

16 Sri Wahyono, "Pengolahan Sampah Organik Dan Aspek Sanitasi," Jurnal Teknologi Lingkungan 2, no. 2 (2011): 113-118, accessed April 29, 2017, http://www.kelair.bppt.go.id/Jtl/2001/vol2-2/01organik.pdf.

17 "Bupati Irsyad Berencana Hidupkan Satu Desa Satu Bank Sampah," News.Detik.Com, last modified 2016, accessed September 29, 2018, https://news.detik.com/berita-jawa-timur/d-3176880/bupati-irsyad-berencanahidupkan-satu-desa-satu-bank-sampah.

18 "BLH Kabupaten Pasuruan Programkan Satu Desa Satu Bank Sampah | TIMES Indonesia,"

Timesindonesia.Co.Id, last modified 2015, accessed September 29, 2018,

https://www.timesindonesia.co.id/read/105093/20150930/185028/blh-kabupaten-pasuruan-programkan-satudesa-satu-bank-sampah/.

${ }^{19}$ Fathurrohman et al., Inisiasi Tata Kelola Manajemen Bank Sampah Berbasis IT Pada Komunitas Bank Sampah Berbasis Sekolah, Pemuda, Dan Masyarakat Di Kabupaten Pasuruan.

20 “Gambaran Umum Pemerintah Kabupaten Pasuruan," Pasuruankab.Go.Id, last modified 2015, accessed September 13, 2015, http://www.pasuruankab.go.id/pages-1-gambaran-umum.html.

Volume 2, Number 2, November 2018 | 158 Implementasi Manajemen Bank Sampah IT pada Komunitas Bank Sampah berbasis Masyarakat, Pemuda, dan Sekolah di Kabupaten Pasuruan 


\section{ENGAGEMENT}

Gurnal Pengabdian Kepada Masyarakat

ISSN : 2579-8375 (Print)

ISSN : 2579-8391 (Online)

Bank Sampah yang baik dengan memanfaatkan aplikasi Bank Sampah. Sehingga, melalui aplikasi ini akan terjalin sharing dan kolaborasi antar Bank Sampah dalam tata kelola manajemen terpadu Bank Sampah di wilayah Kabupaten Pasuruan.

Pada Agustus 2017, Tim Pendamping dari Universitas Yudharta, YISI dan PT. Tirta Investama Pabrik Pandaan melakukan konsolidasi dan koordinasi untuk melakukan inisiasi implementasi aplikasi Bank Sampah berbasis Web dan Android pada Komunitas Bank Sampah di Kabupaten Pasuruan. ${ }^{21}$ Untuk menguji dan mengetahui kemanfaatan aplikasi ini, maka terlebih dahulu dilakukan pendampingan pada Bank Sampah berbasis Masyarakat, pemuda dan Sekolah dengan target Group Bank Sampah OPEK (Pemuda), Bank Sampah TPI (Masyarakat), dan Bank Sampah TK. Al Hidayah dan Bank Sampah PAUD Wanjati (Sekolah) dengan aktifitas pendampingan melalui (1) Saresehan Pegiat Bank Sampah; (2) Workshop Manajemen Tata Kelola Bank Sampah berbasis IT; dan (3) Pendampingan Manajemen Bank Sampah berbasis IT pada komunitas dampingan.

\section{Acting in Finding: Implementasi Aplikasi Bank Sampah pada Komunitas Dampingan}

\section{Saresehan Pegiat Bank Sampah}

Saresehan pegiat Bank Sampah ini di desain untuk membangun persepsi bersama berbagai stakeholders pemerhati lingkungan di Kabupaten Pasuruan dengan melibatkan Komunitas Bank Sampah, Dinas Lingkungan Hidup, Praktisi Lingkungan dan Akademisi di wilayah Kabupaten Pasuruan. Agenda yang telah dilaksanakan pada 7 November 2017 ini berhasil membangun visi misi bersama pemerhati lingkungan hidup untuk mengurai berbagai persoalan sampah di Kabupaten Pasuruan dalam bentuk penguatan kapasitas Pengelola Bank Sampah di Kabupaten Pasuruan.

21 Aplikasi Bank Sampah yang digunakan dalam pendampingan ini memanfaatkan Program Aplikasi SMASH. Lihat "BankSampah.Id | Sistem Online Manajemen Sampah (Smash)," Smash, accessed September 30, 2018, https://banksampah.id/. 


\section{ENGAGEMENT}

Gurnal Pengabdian Kepada Masyarakat

ISSN : 2579-8375 (Print)

ISSN : 2579-8391 (Online)
This work is licensed under a Creative Commons Attribution-ShareAlike 4.0 International License.

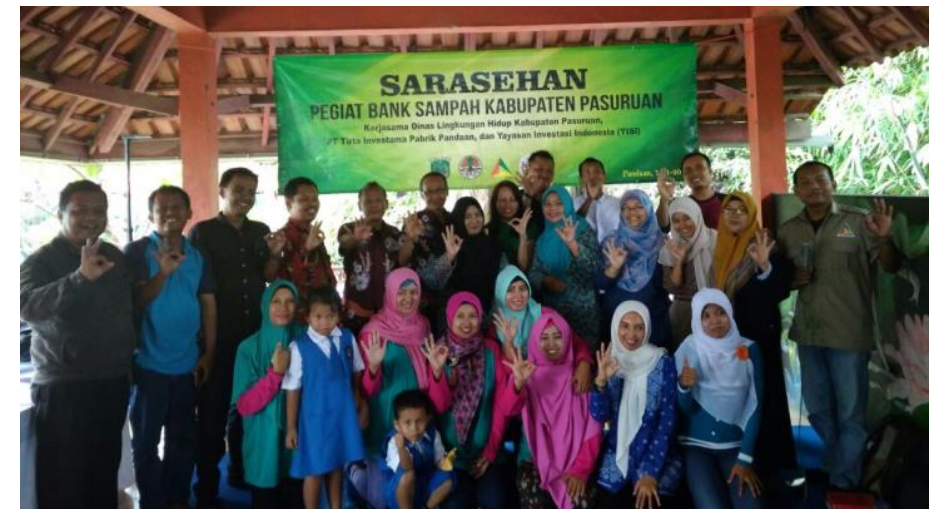

\section{Gambar 1. Saresehan Pegiat Bank Sampah yang melibatkan Multistakholders di Kabupaten Pasuruan}

Dalam Forum tersebut, disepakati bahwa Bank Sampah menjadi bagian penting mitra pemerintah untuk mengurai permasalah sampah, dan pada tahun 2018 ditargetkan dapat mewujudkan berbagai Bank Sampah dari 33 menjadi 140 Komunitas. Dinas Lingkungan Hidup Kabupaten Pasuruan dalam sessi diskusi menyatakan bahwa keberadaan Bank Sampah memiliki fungsi baru, tidak hanya berfungsi pada aspek peningkatan perekonomian warga, namun Bank Sampah yang terbentuk mampu akan mengurangi timbunan sampah di TPA dengan mengurangi sampah pada sumbernya.

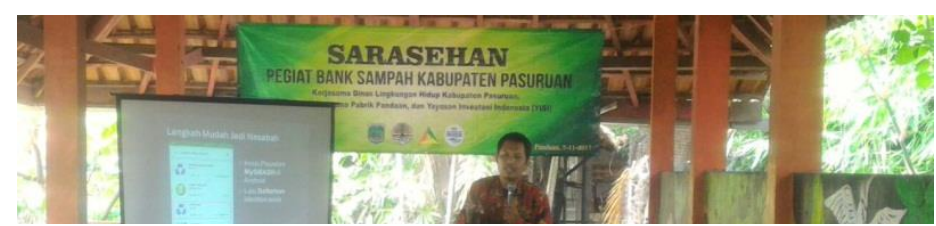

Gambar 2 Sessi Pengenalan Aplikasi Bank Sampah berbasis Web dan Android

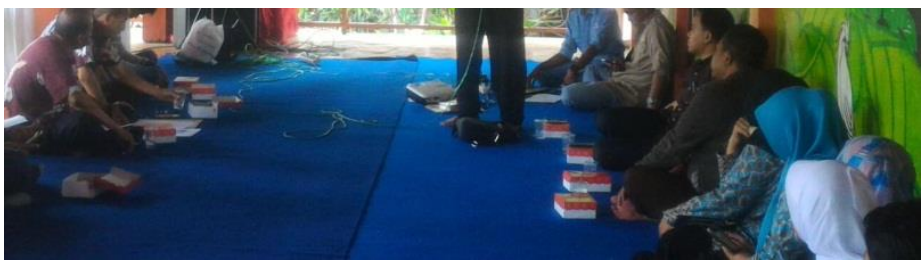

Dalam sessi ini, para peserta saresehan juga sharing terkait dengan strategi pengembangan zerowaste pada sumber pertama dan bagaimana memanfaatkan IT untuk membantu peningkatan kualitas manajemen tata kelola Bank Sampah melalui aplikasi Sistem Online Manajemen Sampah (SMASH). Melalui kegiatan ini mereka menyatakan bahwa dengan sinergi multipihak, baik dari Pemerintah, masyarakat, akademisi, praktisi lingkungan, serta Bank Sampah, maka permasalahan sampah dari sumber pertama akan mampu diurai dengan baik. ${ }^{22}$

22 "Sampah Itu Kotor? Ah, Paradigma Lama... | WartaBromo," Wartabromo.Com, last modified 2017, accessed September 30, 2018, http://www.wartabromo.com/2017/11/07/sampah-itu-kotor-ah-paradigma-lama/.

Volume 2, Number 2, November 2018 | 160 Implementasi Manajemen Bank Sampah IT pada Komunitas Bank Sampah berbasis Masyarakat, Pemuda, dan Sekolah di Kabupaten Pasuruan 


\section{ENGAGEMENT}

Gurnal Pengabdian Kepada Masyarakat

ISSN : 2579-8375 (Print)

ISSN : 2579-8391 (Online)
This work is licensed under a Creative Commons Attribution-ShareAlike 4.0 International License.

\section{Workshop Manajemen Tata Kelola Bank Sampah berbasis IT}

Menindaklanjuti dari agenda Saresehan Bank Sampah, maka tim pendamping melakukan pendampingan secara khusus kepada Bank Sampah yang telah ditentukan, yakni Bank Sampah Opek Gempol (Pemuda), Bank Sampah TPI Beji (Masyarakat), dan Bank Sampah TK. Al Hidayah dan PAUD Wanjati Pandaan (Sekolah) melalui kegiatan "Workshop Manajemen Tata Kelola Bank Sampah berbasis IT" yang telah dilakukan pada 30 November 2017 di Auditorium Rumah Makan Karangjati Pandaan.

Kegiatan ini merupakan pilot project pertama kali yang dikembangkan dalam peningkatan kapasitas Pengelola Bank Sampah berbasis Masyarakat, Pemuda dan Sekolah dengan disupport oleh system IT, sehingga memudahkan pengelola dan masyarakat dalam tata kelola sampah. Sebagaimana disampaikan oleh Mulyono Wibisono dari PT. TIV sebagai berikut:

"Melalui aplikasi ini, harapannya bagaimana nantinya sampah yang sudah dipisah kategorisasinya oleh masyarakat tersebut akan dijemput oleh Bank Sampah seperti sistem penjemputan pada ojek online.
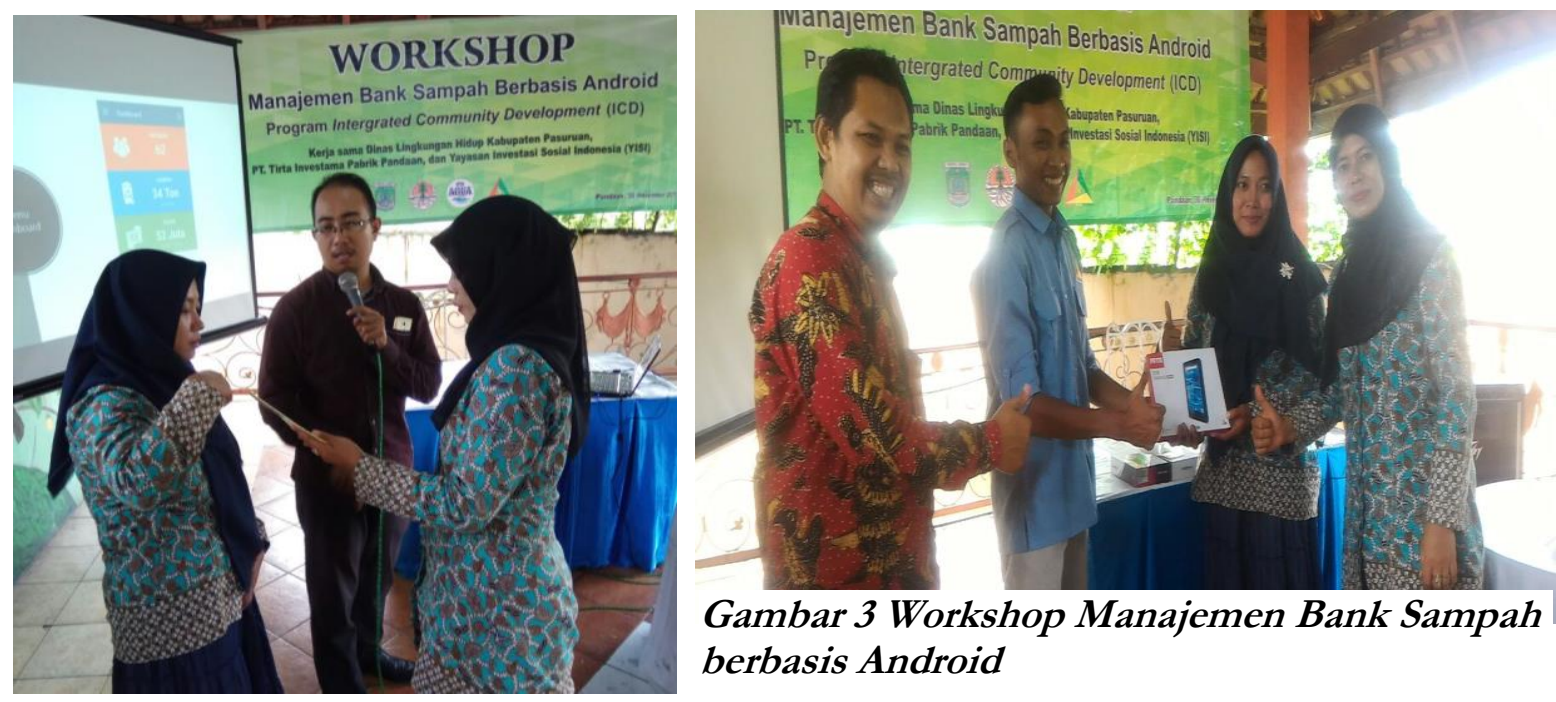

Gambar 3 Workshop Manajemen Bank Sampah berbasis Android

Selain itu juga terbangun transparansi antara pengelola Bank Sampah dengan pibak nasabab dengan adanya nilai/ nominal tiap kategori sampah yang dapat dipantau langsung dari android masing-masing pengelola Bank Sampah maupun nasababnya.,23

Kegiatan ini juga mendapat apresiasi yang baik dari DLH Kabupaten Pasuruan. Suprapto, Kepala Subdin Pengurangan Sampah DLH Kabupaten Pasuruan menyatakan bahwa workshop akan mampu mewujudkan tata kelola sampah yang bersinergi multi pihak agar permasalahan sampah dapat terurai dengan baik.

${ }^{23}$ Fathurrohman et al., Inisiasi Tata Kelola Manajemen Bank. Sampah Berbasis IT Pada Komunitas Bank Sampah Berbasis Sekolah, Pemuda, Dan Masyarakat Di Kabupaten Pasuruan.

Volume 2, Number 2, November 2018| 161 Implementasi Manajemen Bank Sampah IT pada Komunitas Bank Sampah berbasis Masyarakat, Pemuda, dan Sekolah di Kabupaten Pasuruan 


\section{ENGAGEMENT}

Jurnal Pengabdian Kepada Masyarakat

ISSN : 2579-8375 (Print)

ISSN : 2579-8391 (Online)
This work is licensed under a Creative Commons Attribution-ShareAlike 4.0 International License.

Dalam workshop ini, Tim Pendamping langsung memandu para peserta mengenalkan berbagai fitur Aplikasi Bank Sampah tersebut dan langsung mempraktekkan melalui HP Android yang dimiliki oleh peserta. Sebagai tindak lanjut disepakati bahwa mereka akan memperdalam aplikasi Bank Sampah berbasis IT ini untuk diimplementasikan pada komunitas Bank Sampah masing-masing.

\section{Pendampingan Manajemen Bank Sampah berbasis IT di Komunitas}

Untuk lebih meningkatkan kapasitas Pengelola Bank Sampah dalam memanfaatkan Aplikasi Bank Sampah berbasis IT yang sudah dikenalkan melalui Workshop di atas, maka sebagai tindak lanjut, tim pendamping melakukan pendampingan Manajemen Bank Sampah berbasis IT di setiap komunitas dampingan.
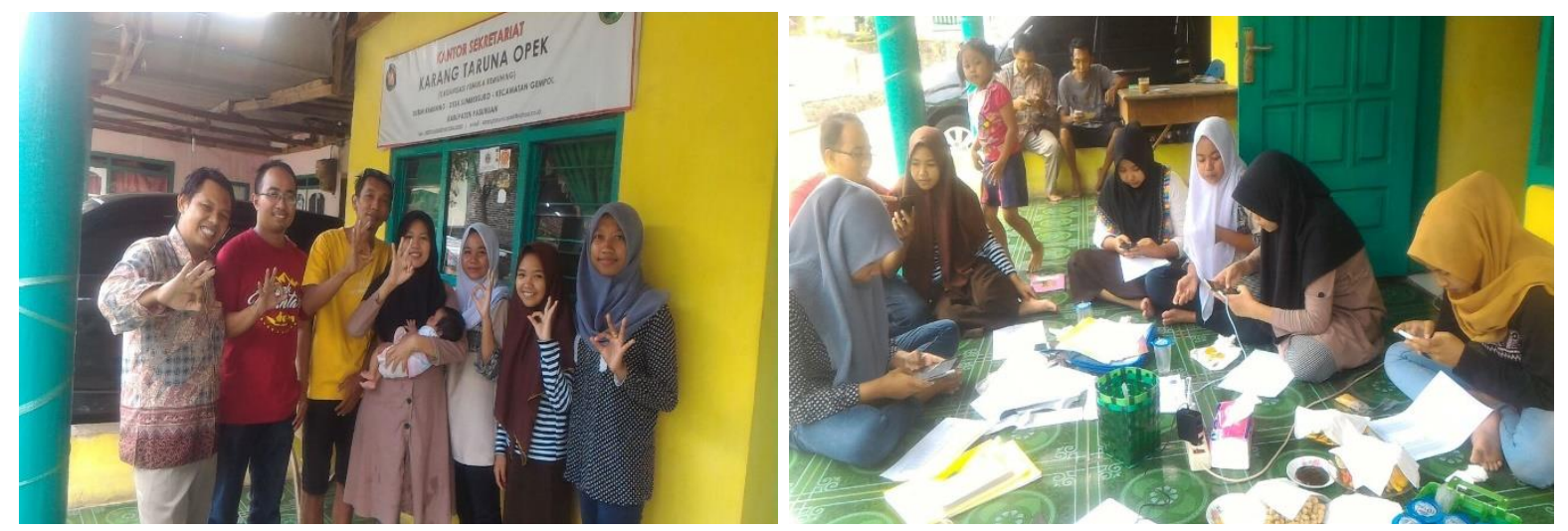

\section{Gambar 4 Pendampingan Manajemen Bank Sampah pada Komunitas Bank Sampah OPEK Gempol}

Waktu pendampingan disesuaikan dengan kesepakatan bersama antara tim pendamping dan komunitas dampingan dan bersifat fleksibel. Sehingga dalam realitasnya, proses pendampingan ini berlangsung hampir satu tahun (Desember 2017-September 2018).

Kegiatan yang berlangsung di Komunitas Bank Sampah masing-masing dalam implementasinya mampu melibatkan lebih banyak peserta dari komunitas itu sendiri, khususnya para pengurus Bank Sampah dan para nasabah yang sebelumnya tidak bisa mengikuti agenda sebelumnya (Saresehan dan Workshop).

Volume 2, Number 2, November 2018 | 162 Implementasi Manajemen Bank Sampah IT pada Komunitas Bank Sampah berbasis Masyarakat, Pemuda, dan Sekolah di Kabupaten Pasuruan 


\section{ENGAGEMENT}

Jurnal Pengabdian Kepada Masyarakat

ISSN : 2579-8375 (Print)

ISSN : 2579-8391 (Online)
This work is licensed under a Creative Commons Attribution-ShareAlike 4.0 International License.

Hasil kegiatan ini mampu mendorong para pengelola Bank Sampah untuk menggunakan dan memanfaatkan Aplikasi Bank Sampah dengan baik. Mulai dari memasukkan data nasabah dan transaksi nasabah yang dihasilkan untuk diinput ke dalam data base, membuat kategori sampah, dan berbagai menu lainnya, misalnya smash pay yang bisa digunakan untuk transaksi digital untuk membeli pulsa atau token listrik. Melalui aplikasi ini, mereka juga dapat mengetahui perkembangan transaksi yang telah mereka lakukan secara mudah dengan fasilitas grafik transaksi yang ada di dalam system aplikasi Bank Sampah tersebut.

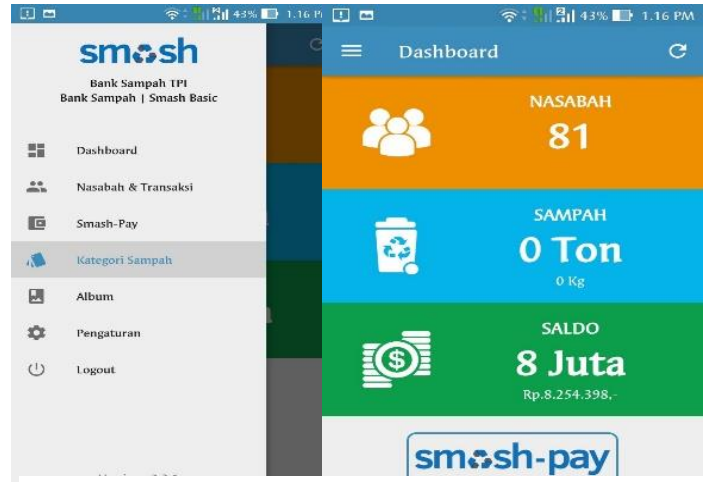

Gambar 5 Hasil Data Base Aplikasi Bank Sampah berbasis Android Bank Sampah TPI Beji Pasuruan

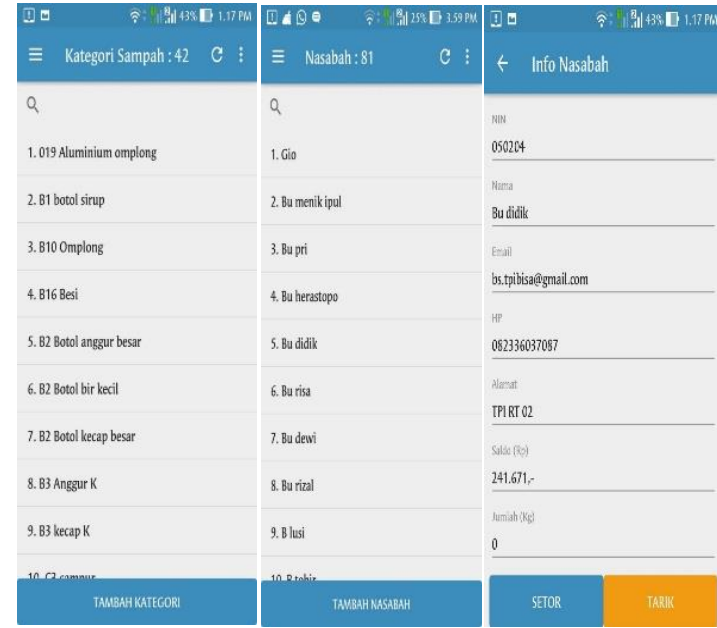

\section{Tantangan, Kendala, dan Solusi dalam Implementasi Dampingan}

Dalam implementasi Program Aplikasi Bank Sampah, terdapat beberapa kendala yang ditemukan selama proses pendampingan, diantaranya:

\section{a. Lemahnya Jaringan Internet.}

Walaupun lokasi dampingan dekat dengan pusat pemerintahan Kecamatan, namun ketiganya memiliki kendala yang sama, yakni lemahnya jaringan sinyal GSM, sehingga akses internet pun menjadi salah satu kendala dalam proses aplikasi Bank Sampah ini. Adapun solusi untuk mengatasi kendala tersebut setiap daerah memiliki cara/solusi yang berbeda-beda sesuai dengan karakteristik daerahnya. Untuk Bank Sampah TPI memanfaatkan jaringan internet free wifi yang terdapat di taman Kelurahan, Bank Sampah OPEK memanfaatkan wifi warung coffee (berbayar) yang berada di depan sekretariat Bank Sampah OPEK. Sedangkan Bank Sampah TK. Al-Hidayah dan PAUD Wanjati harus menggunakan jaringan Internet dari Telkom, karena jaringan internet yang berbasis dari GSM mendapat sinyal yang jelek.

\section{b. Penguasaan dan pemahaman aplikasi Bank Sampah.}

Volume 2, Number 2, November 2018 | 163 Implementasi Manajemen Bank Sampah IT pada Komunitas Bank Sampah berbasis Masyarakat, Pemuda, dan Sekolah di Kabupaten Pasuruan 
Setiap komunitas Bank Sampah memiliki karakteristik dan kemampuan yang berbedabeda dalam memahami aplikasi Bank Sampah. Pengurus Bank Sampah TPI misalnya yang mayoritas adalah ibu-ibu rumah tangga yang secara usia sudah setengah baya, untuk memahami aplikasi Bank Sampah cenderung membutuhkan waktu yang agak lama. Berbeda dengan pengurus Bank Sampah Opek Gempol yang rata-rata berusia remaja dan mayoritas adalah masih sebagai pelajar/mahasiswa sehingga tingkat penguasaan terhadap sistem aplikasi Bank Sampah ini cenderung lebih cepat. Lain halnya dengan pengurus Bank Sampah TK Al-Hidayah dan PAUD Wanjati, karena pengurus terdiri dari Para Wali Murid dan Guru di sekolah, maka waktu proses pendampingan juga disesuaikan dengan jam kelas anak-anak mereka pada waktu sekolah dengan batas maksimal jam 11.00 WIB.

Berbagai karakteristik dan problem di masing-masing komunitas Bank Sampah dalam memahami dan menguasai aplikasi tersebut, maka solusi yang dilakukan adalah melakukan upaya klinik simulasi dan pendampingan secara personal (person to person) di masing-masing pengurus Bank Sampah. Hal ini dimaksudkan untuk memastikan tingkat pengetahuan dan ketrampilan dalam menggunakan aplikasi tersebut. Selain juga memanfaatkan komunikasi sosial media WhatsApp (WA) dengan akun WA Bank Sampah Zero Waste sebagai media konsultasi dalam penggunaan aplikasi Bank Sampah tersebut.

\section{Pembahasan}

Permasalahan sampah di kabupaten Pasuruan menjadi permasalahan yang serius dan sudah di level darurat sampah. Berbagai permasalahan muncul dalam tata kelola sampah, diantaranya keterbatasan lahan TPA Kenep Beji sebagai satu-satunya TPA Sampah di Kabupaten sudah overload dan jauh dari ideal. Keterbatasan sarana TPS dan TPST yang tersebar di wilayah Kabupaten Pasuruan, keterbatasan armada angkut sampah, dan juga keterbatasan tenaga pengelola sampah menambah daftar panjang tentang keterbatasan kemampuan Pemerintah Kabupaten Pasuruan dalam mengelola sampah dengan baik.

Berbagai usaha sudah dilakukan oleh Pemerintah Kabupaten Pasuruan, salah satunya mendorong keterlibatan multipihak untuk mengurai permasalahan ini, salah satunya dengan membentuk Bank Sampah melalui program Satu Desa Satu Bank Sampah. Namun dalam realitasnya, Bank Sampah yang sudah berjalan dengan manajemen yang baik masih terbatas. Baik karena factor komitmen pengelola, tingkat partisipasi masyarakat, sarana prasarana tata kelola Bank Sampah, maupun sinergi antar Bank Sampah dengan Pemerintah maupun dunia industry.

Volume 2, Number 2, November 2018| 164 Implementasi Manajemen Bank Sampah IT pada Komunitas Bank Sampah berbasis Masyarakat, Pemuda, dan Sekolah di Kabupaten Pasuruan 
Hal ini sejalan dengan studi yang dilakukan oleh Anih Sri Suryani yang mengkaji Bank Sampah Malang yang menyatakan bahwa regulasi Pemerintah Daerah untuk mendukung Bank Sampah menjadi factor penting, agar keberlanjutan Bank Sampah menjadi lebih kuat. ${ }^{24}$ Selain itu, kajian dari Donna Asteria dan Heru Heruman menyatakan bahwa sinergi antar Bank Sampah juga menjadi komponen penting dalam tata kelola Bank Sampah yang berkelanjutan pada komunitas Bank Sampah tersebut. ${ }^{25,26}$

Melalui pendampingan ini, telah mampu mendorong Pemerintah Kabupaten Pasuruan untuk lebih memperhatikan Bank Sampah dan melibatkan mereka sebagai bagian penting untuk mengurai permasalahan sampah di Kabupaten Pasuruan. Selain itu, dengan disupport oleh Sistem Aplikasi Bank Sampah berbasis Web dan Android ini, para pengelola Bank Sampah merasakan kemudahan dalam proses tata kelola Bank Sampah yang lebih baik apabila dibandingkan dengan cara sebelumnya.

Walaupun begitu, hasil data di atas juga diketahui bahwa dalam implementasi aplikasi Bank Sampah pada komunitas dampingan, masih terdapat kendala dan hambatan, baik terkait dengan akses internet, kemampuan pengelola Bank Sampah dalam memahami system aplikasi ini, sampai dengan keterbatasan waktu untuk mempelajari dan menerapkan aplikasi ini sebagai bagian penting dalam tata kelola Bank Sampah.

\section{Kesimpulan}

Beragam aktifitas dalam kegiatan pendampingan Managemen Aplikasi Bank Sampah Berbasis IT pada umumnya mendapat sambutan dan apresiasi yang baik bagi para pengelola Bank Sampah di Kabupaten Pasuruan. Namun, dalam proses transisi dari tata kelola Bank Sampah dari berbasis manual sampai ada perubahan dengan memanfaatkan IT membutuhkan proses, waktu serta kemauan dari para pengelola Bank Sampah, sehingga aplikasi ini dapat dimanfaatkan secara maksimal.

${ }^{24}$ Anih Sri Suryani, "PERAN BANK SAMPAH DALAM EFEKTIVITAS PENGELOLAAN SAMPAH (STUDI KASUS BANK SAMPAH MALANG)," Jurnal Aspirasi 5, no. 1 (2014): 71-84, accessed September 30, 2018, http://jurnal.dpr.go.id/index.php/aspirasi/article/view/447.

25 Donna Asteria and Heru Heruman, "BANK SAMPAH SEBAGAI ALTERNATIF STRATEGI PENGELOLAAN SAMPAH BERBASIS MASYARAKAT DI TASIKMALAYA (Bank Sampah (Waste Banks) as an Alternative of Community-Based Waste Management Strategy in Tasikmalaya)," Jurnal Manusia dan Lingkungan 23, no. 1 (February 28, 2016): 136, accessed September 30, 2018, https://jurnal.ugm.ac.id/JML/article/view/18783.

${ }^{26}$ Lihat juga kajian Melyanti dalam pola kemitraan multistakholders, dalam Imelda Merry Melyanti, "Pola Kemitraan Pemerintah, Civil Society, Dan Swasta Dalam Program Bank Sampah Di Pasar Baru Kota Probolinggo," Kebijakan dan Manajemen Publik. 2, no. 1 (2014): 1-9, accessed September 30, 2018, http://journal.unair.ac.id/filerPDF/kmpe0736a7a4efull.pdf.

Volume 2, Number 2, November 2018 | 165 Implementasi Manajemen Bank Sampah IT pada Komunitas Bank Sampah berbasis Masyarakat, Pemuda, dan Sekolah di Kabupaten Pasuruan 


\section{ENGAGEMENT}

Jurnal Pengabdian Kepada Masyarakat

ISSN : 2579-8375 (Print)

ISSN : 2579-8391 (Online)
This work is licensed under a Creative Commons Attribution-ShareAlike 4.0 International License.

Dari berbagai rangkaian pendampingan tersebut, dapat direkomendasikan bahwa untuk mengurai permasalahan sampah di Kabupaten Pasuruan, maka sinergi multipihak sangat diperlukan. Oleh karena itu, maka Pemerintah Kabupaten Pasuruan diharapkan dapat mendorong dan menfasilitasi Bank Sampah di Kabupaten Pasuruan agar dapat saling bersinergi dengan didukung sistem IT Aplikasi Bank Sampah yang terintegratif.

\section{Ucapan Terimakasih}

Terimakasih disampaikan kepada berbagai pihak yang telah mendukung proses pelaksanaan pendampingan masyarakat ini, diantaranya Yayasan Investasi Sosial Indonesia, PT. Tirta Investama Pabrik Pandaan, dan LPPM Universitas Yudharta. Wabil khusus, ucapan terimakasih juga disampaikan kepada Subdit Penelitian danPengabdian Kepada Masyarakat, Direktorat Pendidikan Tinggi Keagamaan Islam, Kemenag RI, sehingga pendampingan pada komunitas Wanjati Pandaan dapat terlaksana dengan baik. 


\section{Daftar Referensi}

Aji, Fafit Rahmat, Mulyono Wibisono, Rony Rusdiansyah, and Yovi Kurniawan. "Pengembangan PAUD Pro-Lingkungan Hidup Melalui Scalling Dalam Program Integrated Community Development (ICD) PT. TIV." At-Tajdid: Jurnal Ilmu Tarbiyah 5, no. 1 (2016): 129-150. Accessed April 29, 2017.2 http://ejournal.stitmuhpacitan.ac.id/index.php/attajdid/article/view/78.

Asteria, Donna, and Heru Heruman. "BANK SAMPAH SEBAGAI ALTERNATIF STRATEGI PENGELOLAAN SAMPAH BERBASIS MASYARAKAT DI TASIKMALAYA (Bank Sampah (Waste Banks) as an Alternative of Community-Based Waste Management Strategy in Tasikmalaya)." Jurnal Manusia dan Lingkungan 23, no. 1 (February 28, 2016): 136. Accessed September 30, 2018. https://jurnal.ugm.ac.id/JML/article/view/18783.

Fathurrohman, Amang. "Rintisan Pendidikan Anak Usia Dini Suku Tengger Di Wilayah Terpencil Dusun Surorowo Desa Kayukebek Kecamatan Tutur Kabupaten Pasuruan.” In 1st Annual Conference for Muslim Scholars Kopertais Wilayah IV Surabaya, 408-416. Surabaya: Kopertais Wilayah IV Surabaya, 2017. http://proceedings.kopertais4.or.id/index.php/ancoms/article/view/42.

Fathurrohman, Amang, M. Dayat, M. Daimul Abror, Zainul Ahwan, Lukman Hakim, Syukur Sugeng Apriwiyanto, and Mulyono Wibisono. Inisiasi Tata Kelola Manajemen Bank Sampah Berbasis IT Pada Komunitas Bank Sampah Berbasis Sekolah, Pemuda, Dan Masyarakat Di Kabupaten Pasuruan. Kabupaten Pasuruan, 2018.

Fathurrohman, Amang, M Dayat, Syukur Sugeng Apriwiyanto, and Mulyono Wibisono. "Shodaqoh Sampah Usia Dini: Implementasi Program Shodaqoh Sampah Pada Pendidikan Usia Dini Wanjati Junior Pandaan Pasuruan.” PROCEEDINGS: Annual Conference for Muslim Scholars 1, no. Series 2 (2018): 711-720.

Kementerian Negara Lingkungan Hidup. Rencana Aksi Nasional Dalam Menghadapi Perubahan Iklim. Indonesia, 2007.

Melyanti, Imelda Merry. "Pola Kemitraan Pemerintah, Civil Society, Dan Swasta Dalam Program Bank Sampah Di Pasar Baru Kota Probolinggo." Kebijakan dan Manajemen Publik 2, no. 1 (2014): 1-9. Accessed September 2018. http://journal.unair.ac.id/filerPDF/kmpe0736a7a4efull.pdf.

Muhammad Fahmi. “2018, Wajah TPA Kenep Bakal Berubah Jadi Begini.” Radar Bromo. Last modified 2017. Accessed $\quad$ September 2018. https://radarbromo.jawapos.com/read/2017/11/02/23918/2018-wajah-tpa-kenep-bakalberubah-jadi-begini.

Purwanta, Wahyu. "Penghitungan Emisi Gas Rumah Kaca (GRK) Dari Sektor Sampah Perkotaan Di Indonesia." Jurnal Teknik Lingkungan 10, no. 1 (2009): 1-8.

Rossi. "Jumlah Bank Sampah Jauh Dari Ideal." Kabarbromoterkini.Com. Last modified 2015. Accessed May 4, 2017. http://www.kabarbromoterkini.com/2015/04/24/jumlah-banksampah-jauh-dari-ideal/3/.

Suryani, Anih Sri. "PERAN BANK SAMPAH DALAM EFEKTIVITAS PENGELOLAAN

Volume 2, Number 2, November 2018| 167

Implementasi Manajemen Bank Sampah IT pada Komunitas Bank Sampah berbasis Masyarakat, Pemuda, dan Sekolah di Kabupaten Pasuruan 
SAMPAH (STUDI KASUS BANK SAMPAH MALANG)." Jumal Aspirasi 5, no. 1 (2014): 71-84. Accessed September 30, 2018. http://jurnal.dpr.go.id/index.php/aspirasi/article/view/447.

Susandi, Armi, Indriani Herlianti, Mamad Tamamadin, and Irma Nurlela. "Dampak Perubahan Iklim Terhadap Ketinggian Muka Laut Di Wilayah Banjarmasin.” Jurnal Ekonomi Lingkungan 12, no. 2 (2008): 5-8. http://blog.umy.ac.id/ghea/files/2011/12/Dampak-PerubahanIklim-Terhadap-Ketinggian-Muka-Laut-Banjarmasin.pdf.

Tim Penyusun CBR UIN Sunan Ampel Surabaya. Community Based Research: Sebuah Pengantar. Surabaya: SILE/LLD, 2015.

Wahyono, Sri. "Pengolahan Sampah Organik Dan Aspek Sanitasi." Jurnal Teknologi Lingkungan 2, no. 2 (2011): 113-118. Accessed April 29, 2017. http:/ /www.kelair.bppt.go.id/Jtl/2001/vol2-2/01organik.pdf.

Wiyono, Suryo. "Perubahan Iklim Dan Ledakan Hama Dan Penyakit Tanaman." Perubaban Iklim Dan Ledakan Hama Dan Penyakit Tanaman. Jakarta: KEHATI, 2007. http://repository.ipb.ac.id/handle/123456789/30756.

"BankSampah.Id | Sistem Online Manajemen Sampah (Smash)." Smash. Accessed September 30, 2018. https://banksampah.id/.

"BLH Kabupaten Pasuruan Programkan Satu Desa Satu Bank Sampah | TIMES Indonesia." Timesindonesia.Co.Id. Last modified 2015. Accessed September 29, 2018. https://www.timesindonesia.co.id/read/105093/20150930/185028/blh-kabupatenpasuruan-programkan-satu-desa-satu-bank-sampah/.

"Bupati Irsyad Berencana Hidupkan Satu Desa Satu Bank Sampah." News.Detik.Com. Last modified 2016. Accessed September 29, 2018. https://news.detik.com/berita-jawa-timur/d3176880/bupati-irsyad-berencana-hidupkan-satu-desa-satu-bank-sampah.

“Gambaran Umum Pemerintah Kabupaten Pasuruan.” Pasuruankab.Go.Id. Last modified 2015. Accessed September 13, 2015. http://www.pasuruankab.go.id/pages-1-gambaranumum.html.

"Sampah Itu Kotor? Ah, Paradigma Lama... | WartaBromo." Wartabromo.Com. Last modified 2017. Accessed September 30, 2018. http://www.wartabromo.com/2017/11/07/sampahitu-kotor-ah-paradigma-lama/.

“Tuntaskan TPA Kenep, Bebaskan 2250 M2 Lahan.” Pasuruankab.Go.Id. Accessed January 23, 2016. pasuruankab.go.id/berita-2077-tuntaskan-tpa-kenep-bebaskan-2250-m2-lahan.html.

Volume 2, Number 2, November 2018 | 168

Implementasi Manajemen Bank Sampah IT pada Komunitas Bank Sampah berbasis Masyarakat, Pemuda, dan Sekolah di Kabupaten Pasuruan 